DEPÓSITO LEGAL ZU2020000153

Esta publicación científica en formato digital

es continuidad de la revista impresa

ISSN 0041-8811

E-ISSN 2665-0428

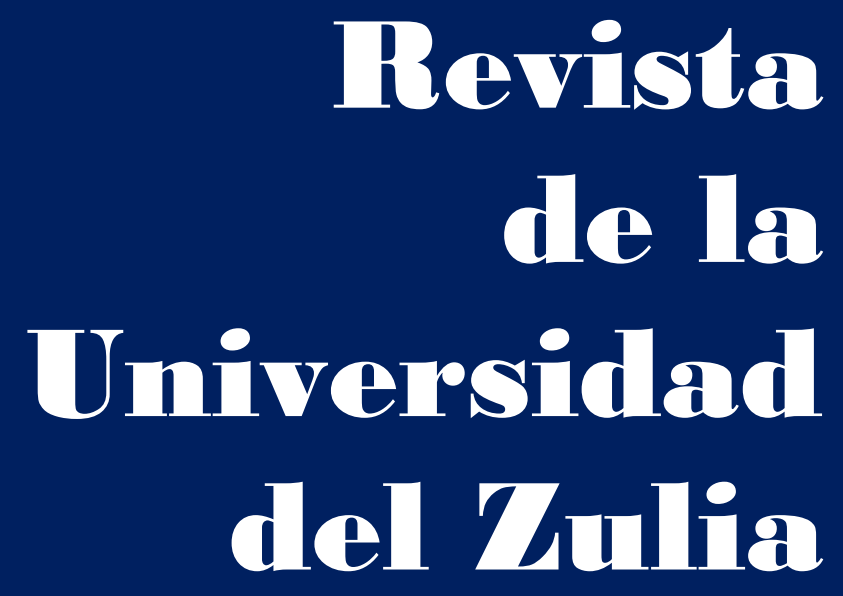

Fundada en 1947

por el Dr. Jesús Emrique Lossada

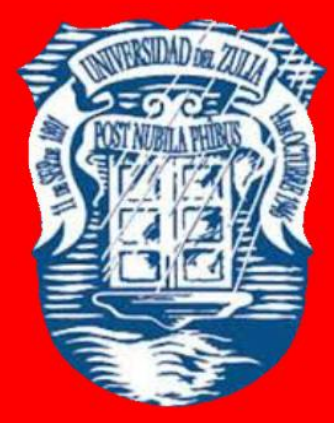

Ciencias

Sociales

y Arte

Año $12 \quad N^{\circ} 34$

Septiembre - Diciembre 2021

Tercera Época

Maracaibo-Veneruela 


\title{
El enfoque geohistórico como estrategia para el abordaje de la dinámica espacial
}

\author{
Gerardo Valera *
}

RESUMEN

El presente trabajo introductorio del Número 34 de la Revista de la Universidad del Zulia, tiene como propósito valorar al enfoque geohistórico como una estrategia para el abordaje de la dinámica espacial desde lo inter y transdisciplinario, a partir de los aportes teóricos de: Palencia (2003), Ceballos (2007), Morillo et al (2010), Morales (2014), Ramírez y Puerta (2013). El enfoque geohistórico concibe el espacio desde un punto de vista humano, trascendiendo lo meramente geográfico e histórico, para dialogar con el conjunto de las ciencias humanas. Este abordaje inter y transdisciplinario permite concebir el espacio desde diferentes matices, para emitir juicios más aproximados a la realidad

PALABRAS CLAVE: geografía histórica; historia; geografía humana; enfoque interdisciplinario.

\section{The geohistorical approach as a strategy for addressing spatial dynamics}

ABSTRACT

The present introductory work of issue 34 of the Journal of the University of Zulia, aims to assess the geohistorical approach as a strategy for the approach of spatial dynamics from the interdisciplinary, from the theoretical contributions of: Palencia (2003), Ceballos (2007), Morillo et al (2010), Morales (2014), Ramírez and Puerta (2013). The geohistorical approach conceives space from a human point of view, transcending the merely geographical and historical, to dialogue with the whole of the human sciences. This interdisciplinary approach allows to conceive the space from different nuances, to make judgments closer to reality

KEYWORDS: historical geography; history; human geography; interdisciplinary approach.

* Profesor de la Universidad del Zulia. Facultad de Humanidades y Educación. División de Estudios para Graduados. Doctorado en Ciencias Humanas. Maracaibo - Venezuela. ORCID: https://orcid.org/0000-0001-6478-1553. E-mail: valeragerardo@gmail.com 
REVISTA DE LA UNIVERSIDAD DEL ZULIA. 3época. Año 12 N 34, 2021

Gerardo Valera // El enfoque geohistórico como estrategia para el abordaje de la dinámica espacial, 3-7 DOI: http://dx.doi.org/10.46925//rdluz.34.01

La Geohistoria es la ciencia fundada por el historiador francés Fernand Braudel (1902 - 1985), quien inspirado en sus homólogos Lucien Febvre y Marc Bloch, escribió en 1949: "El Mediterráneo y el mundo mediterráneo en la época de Felipe II (originalmente La Méditerranéeet le Monde Méditerranéen a l'époque de Philippe II).

En Venezuela el liderazgo científico de la Geohistoria lo ejerció el profesor e investigador Ramón Adolfo Tovar López (1923-2018) de la Universidad Pedagógica Experimental Libertador (UPEL). Esta herencia braudeliana tiene su génesis a partir de sus estudios realizados en el Instituto de Geografía de la Universidad de Estrasburgo (Francia). Al llegar a su tierra natal y en la búsqueda de una teoría propia y que fuese capaz de explicar la realidad del espacio venezolano establece el carácter de la geografía como ciencia social afirmando que ésta “...explica la organización diferenciada del espacio estructurado por los grupos humanos dentro de condiciones históricas determinadas" (Tovar, 1996), dando a la geografía un papel de vanguardia en el estudio de los fenómenos sociales que se presenta en la comunidad, y haciendo de ésta una ciencia de síntesis, de análisis y relaciones de esos acontecimiento; atendiendo además, las posibles influencias que genera al estilo de vida del individuo.

"El Enfoque Geohistórico se desprende de la concepción geográfica que entiende al espacio como un producto concreto o síntesis de la acción de los grupos humanos sobre su medio ambiente para su necesaria conservación y reproducción sujeto a condiciones históricas determinadas" (Tovar, 1986:23), permitiendo conocer e intervenir las distintas realidades que viven las comunidades en un tiempo determinado, es decir, participan conjuntamente las metodologías tanto de la geografía como de la historia anticipado por un proceso de reflexión y razonamiento (Orella, 2010).

La Geohistoria busca modelos de actuación mixtos, fruto de una observación espacio - temporal y entra en campos de investigación propios como son los medios y sistemas de producción dentro de su soporte espacial. Al respecto, Morales (2014: 288) aclara que la Geohistoria "es un saber que surge desde la geografía como disciplina que la origina, edificada según este práctico y novedoso diálogo constructivo entre dos disciplinas, en nuestro caso geografía e historia".

Sin embargo, queda claro que no es suficiente marcar en un espacio y tiempo concretos los cambios del medio natural en función de la actuación tecnológica humana. Un análisis 
REVISTA DE LA UNIVERSIDAD DEL ZULIA. $3^{a}$ época. Año $12 \mathrm{~N}^{\circ}$ 34, 2021

Gerardo Valera // El enfoque geohistórico como estrategia para el abordaje de la dinámica espacial, 3-7 DOI: http://dx.doi.org/10.46925//rdluz.34.01

geohistórico exige la combinación de los resultados que en un momento dado devienen de las opciones humanas y las determinaciones reales de la naturaleza. La Geohistoria detecta en cada época histórica el juego peculiar de opciones humanas y de determinismos naturales.

Se trata entonces de concebir el espacio desde un punto de vista humano. La concepción geohistórica del espacio conduce a su análisis objetivo, teniendo en cuenta que la realidad es compleja, heterogénea y multivariable, pero que necesita de la contribución de un contingente humano con sentido de pertenencia:

"la Geohistoria es una ciencia que diagnostica pero que supone compromiso: ella es fiel a la condición del pueblo como la solidaridad del grupo humano con su territorio, así como la nación: una comunidad estable, históricamente formada de lengua, territorio, vida económica, manifestada en la comunidad, en su cultura" (Tovar, 1986:63).

Por su parte, Ramírez y Puerta (2013) consideran que las condiciones actuales que vive la humanidad obligan a estrechar el diálogo entre las disciplinas científicas, en la búsqueda de condiciones que favorezcan cada día más a los seres vivos y a los recursos naturales. Esta condición aparece presente en el Enfoque Geohistórico, pues se vale de su metodología para la búsqueda de la resolución de los problemas presentes en el entorno. Al respecto:

"Lo geohistórico se plantea con una visión interdisciplinaria, donde convergen la vertiente sociológica, antropológica e histórica, además de la económica para la definición de una espacialidad producto de condiciones históricas dadas. Conlleva a la identificación de "las permutaciones Geohistóricas" como vía para descubrir los signos del cambio a fin de dar las pautas para acciones concretas que atiendan a las necesidades de los grupos humanos" (Ceballos, 2007: 236).

El enfoque geohistórico, entonces, brindará los elementos necesarios para reflexionar sobre el entorno inmediato, bajo escenarios auténticos y reales en un momento histórico determinado, todo esto bajo una concepción que trasciende la disciplina meramente geográfica. Al abordar un espacio desde lo geohistórico,

“...en esencia persiste una propuesta de interdisciplinariedad y transdisciplinariedad; en ella visualizamos la posibilidad de aprehender la realidad, comprenderla y explicarla en su complejidad. Lo geohistórico invita a repensar el espacio social construido por los grupos humanos en condiciones históricas determinadas" (Ramírez y Puerta, 2013: 67). 
REVISTA DE LA UNIVERSIDAD DEL ZULIA. 3época. Año 12 N 34, 2021

Gerardo Valera // El enfoque geohistórico como estrategia para el abordaje de la dinámica espacial, 3-7 DOI: http://dx.doi.org/10.46925//rdluz.34.01

Sin duda que el abordaje inter y transdisciplinario permite concebir el espacio desde diferentes matices para emitir juicios más aproximados a la realidad a diferentes escalas. Por esta razón, Palencia (2003: 38) establece que,

"El Enfoque Geohistórico contribuye al estudio del espacio desde diversas perspectivas: socio históricas, socio - espacial, socio - económica, socio - cultural, para una mejor aproximación, interpretación y comprensión del espacio a escala micro, meso y macro".

De modo que el abordaje del espacio desde lo geohistórico garantizaría la conexión con otras estructuras del conocimiento, donde no solo se retroalimentaría de la geografía y de la historia, sino involucraría las demás ciencias humanas. Al respecto, Morales (2014: 288) destaca el aspecto interdisciplinar de la Geohistoria y enuncia que "su condición de saber relacional, le permite establecer vasos comunicantes con lo antropológico, lo sociológico y lo histórico manifestados y concretizados en la estructura del espacio".

En los tiempos actuales, cada día se hace más prioritario que todo individuo adquiera destrezas que le permita intervenir su espacio y que sea capaz de definir, comprender y analizar su propio entorno, a fin de generar la interpretación de los distintos fenómenos encontrados. Es por ello que Ramírez y Puerta (2013: 73) aseguran que "la pertinencia del enfoque geohistórico, en tiempos de globalización, radica en la posibilidad de producir teoría geográfica, asumiendo las especificidades de nuestros propios espacios".

De esta manera, al tomar el enfoque geohistórico como metodología de aprendizaje de la geografía, se está asumiendo el compromiso de incursionar en el campo científico a través de la investigación y, por ende, de las diferentes fases del método científico, como lo son: la observación, la formulación de hipótesis y la refutación de las mismas, permitiendo llegar a la emisión de teorías que explican el proceso anterior. En efecto, "El aprendizaje geográfico que se pretende, tiene la pertenencia de inducir al estudio de lo local, el observar el orden natural y el orden creado, la ubicación del espacio y del tiempo" (Bejas et al., 2006: 13).

En el mismo orden de ideas, Palencia (2003) sostiene que el enfoque geohistórico brinda la oportunidad de interpretar las formas, estructuras y dinámicas de los centros poblados, a partir de los puntos de vista social, económico y cultural, al mismo tiempo que nos permite establecer una visión general de los elementos que integran al conjunto espacial en sus diferentes escalas. 
REVISTA DE LA UNIVERSIDAD DEL ZULIA. $3^{a}$ época. Año $12 \mathrm{~N}^{\circ}$ 34, 2021

Gerardo Valera // El enfoque geohistórico como estrategia para el abordaje de la dinámica espacial, 3-7 DOI: http://dx.doi.org/10.46925//rdluz.34.01

En consecuencia, el enfoque geohistórico conduce a la elaboración de un sistema conceptual, por medio del cual es posible estudiar la realidad y clasificar los hechos observados, sistematizándolos mediante generalizaciones empíricas que permiten aprehender el entorno, lo que se traduce en conocimiento y mejor calidad de vida.

\section{Referencias}

Bejas, M; Apitz, A y Gouveia, E. (2006) Propuesta de contenidos conceptuales para la enseñanza-aprendizaje de la geografía local desde el enfoque Geohistórico. Revista Omnia $\begin{array}{llllllll}\text { Año } & \text { 12, No. } & 2 & \text { (2006) } & \text { pp. } & - & \text { 36. Disponible en }\end{array}$ https://produccioncientificaluz.org/index.php/omnia/issue/view/866

Ceballos, B. (2007) La Educación Geográfica en la Formación del Ciudadano como Eje del Currículo del Liceo Bolivariano en Venezuela. Didáctica Geográfica, 3. época 9. pp. 233-242 Recuperado a partir de https://didacticageografica.agegeografia.es/index.php/didacticageografica/article/view/15

Ceballos, B. (2003) El Diagnóstico Geohistórico y la Intervención en las Comunidades. Caso Lobatera - Táchira. lera Edición. UPEL

Morales, O. (2014) Epistemología de la Geohistória. Revista Geoenseñanza, Vol. 19, 2014 (2) julio - diciembre / p. 283-288. Disponible en:

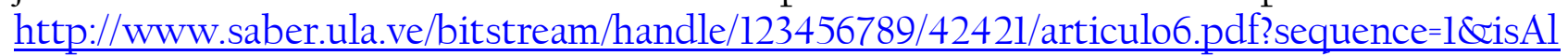
lowed $=y$

Orella, J. (2010) Geohistória. Revista Lurralde: invest. Espac. Nro. 33. Pp. 233- 310. https://www.ingeba.org/lurralde/lurranet/lur33/33orellaateneo/33orelateneo.pdf

Palencia, Y. (2003). Praxis investigativa geohistórica para una representación cartográfica de un espacio rural. Geoenseñanza. Vol. 3 (2) p. 25 - 39. Táchira - Venezuela. Disponible en:

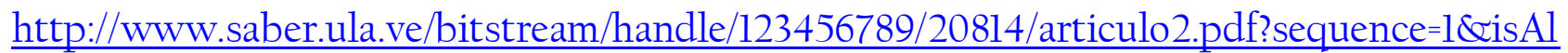
lowed $=\mathrm{y}$

Ramírez, A. y Puerta C. (2013) Geohistoria. Propuesta metodológica pertinente en la enseñanza de la Geografía e Historia. Revista Electrónica Diálogos Educativos Vol. 13 Nro. 25 año 2013.http://www.dialogoseducativos.cl/revistas/n25/ramirez

Tovar, R. (1986). El Enfoque Geohistórico. Biblioteca de la Academia Nacional de la Historia. No.77 Caracas, Venezuela

Valera, G. (2009). Enfoque Geohistórico: Alternativa en el aprendizaje de la geografía desde la interacción escuela-comunidad. Trabajo especial de Grado para optar al Título de Magíster Scientiarum en Geografía, Mención Docencia. LUZ, Maracaibo Venezuela. 